\title{
Sensitisation of gastrointestinal tract afferents
}

\author{
S B McMahon
}

Gut 2004;53(Suppl II):ii13-ii15

Sensory innervation of the viscera serves a number of important functions, including regulation of visceral motility and secretory activity, and transmission of visceral sensations, including pain. There are many ways in which the sensitivity of visceral sensory neurones might be modulated, and these are discussed. Altered sensory neurone responsiveness may contribute to pathophysiological states such as irritable bowel syndrome, and the mechanisms leading to sensory neurone sensitisation offer novel targets for the treatment of such disorders.

Correspondence to: Professor S B McMahon, Centre for Neuroscience Research, Kings College London, Guy's Campus, Hodgkin Building, London Bridge, London SE I IUL, UK; stephen.mcmahon@ kcl.ac.uk

\section{SUMMARY}

Sensory innervation of the viscera in general and the gastrointestinal tract in particular serves a number of important functions, including regulation of visceral motility and secretory activity, and transmission of visceral sensations, including pain. However, the transduction properties of visceral afferents are not stable and can be altered by a large number of factors. The word plasticity is often used to describe these altered properties, although it is worth noting that this term has no formal definition and is taken to mean different things by different authors. In the context of visceral sensory neurones, functionally relevant forms of plasticity are those that affect the encoding and transmission of sensory information. Increased excitability of sensory neurones can have dramatic functional consequences, and may contribute to chronic pain states and conditions of hyper- or dysreflexia.

There are two broad types of sensory neurone plasticity that need to be distinguished. Firstly, rapid onset peripheral sensitisation (or desensitisation) of sensory terminals, arising without altered gene expression, and secondly, a slower onset phenotypic change in sensory neurone properties as a consequence of altered gene expression. This latter form of plasticity can affect sensory transmission in a variety of ways, and both forms of plasticity are discussed in more detail below.

\section{PERIPHERAL SENSITISATION}

Tissue injury and inflammation and a great many algesic chemicals produce changes in the stimulus-response functions of the primary sensory neurone terminals in peripheral tissues. If the stimulus-response function shows a leftward shift, the neurone is sensitised and a greater afferent barrage is generated for a given stimulus. Less studied, but potentially important, is the fact that neurones can be desensitised and show rightward shifts in stimulus-response functions.

As illustrated in fig $1 \mathrm{~A}$, stimuli that trigger sensitisation may activate $G$ protein coupled receptors in the nociceptor terminal (for instance, prostanoids acting at EP receptors, ${ }^{1}$ adenosine triphosphate (ATP) acting at P2Y receptors, ${ }^{2}$ bradykinin at B2 receptors, ${ }^{3}$ and some agents acting at chemokine receptors). ${ }^{4}$ Alternatively, there may be stimuli that activate ligand gated receptors (such as capsaicin or heat acting on VRl, ${ }^{5}$ or ATP acting at P2X receptors). ${ }^{6}$ Finally, several trophic factors and cytokines acting at tyrosine kinase receptors may cause sensitisation (most notably, nerve growth factor (NGF) acting at tyrosine kinase A (trkA) receptors)..$^{78}$

As shown in fig 1B, these different stimuli recruit a variety of intracellular signalling cascades, including protein kinase A (PKA) and protein kinase $\mathrm{C}$ (PKC), ${ }^{9-11}$ or the map kinase extracellular regulated kinase (ERK) $1 / 2 .{ }^{12}{ }^{13}$ The final effector mechanism underlying sensitisation of nociceptors is also quite variable and, as illustrated in fig IC, can involve modulation (often by phosphylation) of $\mathrm{Na}^{+}, \mathrm{K}^{+}$, or $\mathrm{Ca}^{++}$ channels. ${ }^{14}{ }^{15}$ Modulation of these channels can affect the ease with which the membrane can be brought to threshold. Clearly this would affect the responsiveness of the neurone to all forms of stimulation. Another more specific means of affecting responsiveness is by modulation via phosphylation of some receptors such as $\mathrm{VR}^{16}$ and P2X. ${ }^{17}$ Modulation of VRl has been particularly well studied and it is clear that its sensitisation can be so large as to lead to activation of the receptor at body temperatures. ${ }^{218}$ It is also clear that a great many stimuli are coupled to VRl sensitisation. It is worth noting that to date we have no strong data about the molecular nature of the mechanical transducer, although it is clear that sensitisation to mechanical stimulation can readily occur in visceral sensory neurones. ${ }^{19}$ The absence of information is unfortunate as it is this form of sensitisation of visceral sensory neurones that is likely to have the most important functional consequences.

Peripheral sensitisation of neurones typically arises within seconds of application of an adequate stimulus and persists, to a transient

Abbreviations: ATP, adenosine triphosphate; NGF, nerve growth factor; $E R K$, extracellular regulated kinase; trkA, tyrosine kinase A; PKA, protein kinase A; PKC, protein kinase $\mathrm{C}$ 
A Stimuli

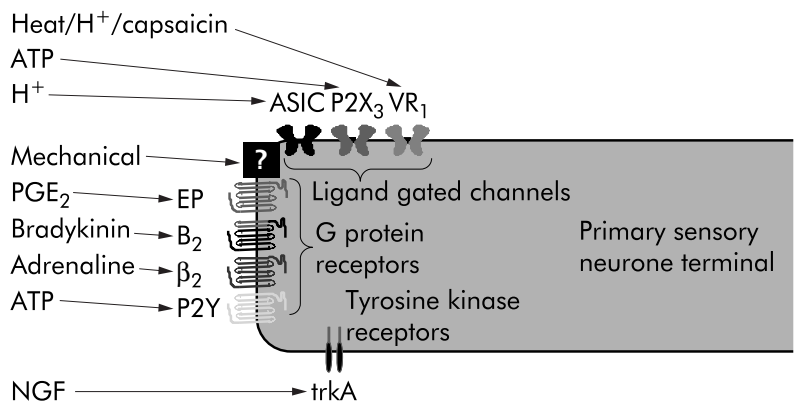

B Pathways
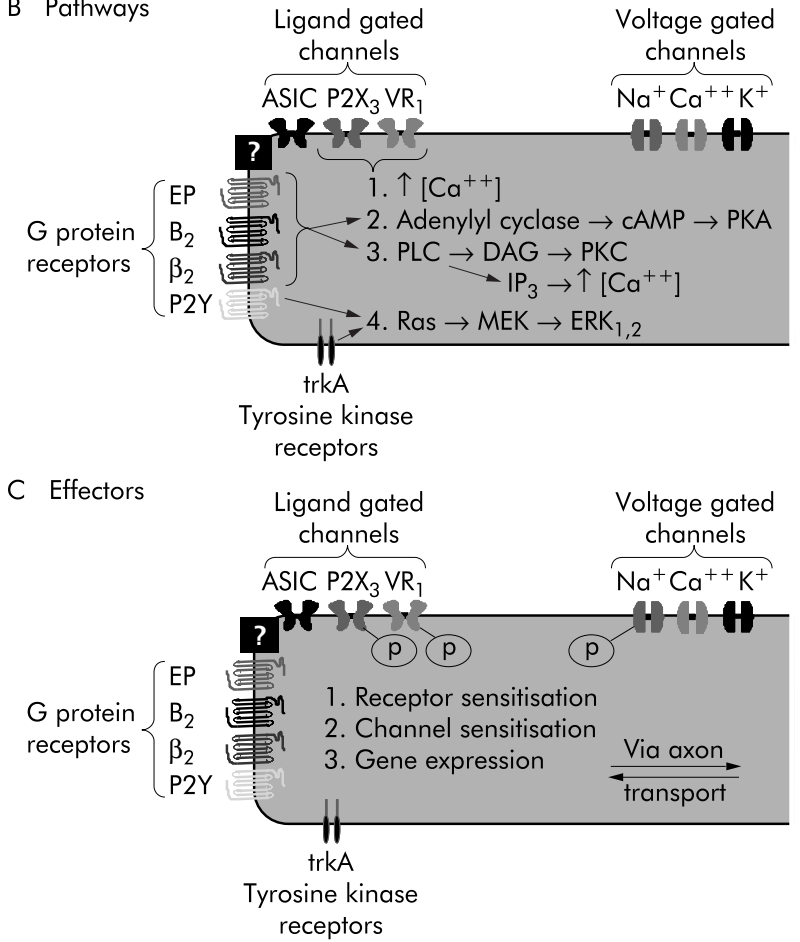

Figure 1 Modulation of primary sensory neurone sensitivity. (A) A list (on the left) of many of the stimuli which can lead to sensory neurone sensitisation. (B) Illustration of the second messenger cascades by which sensitising stimuli induce their local effects. (C) Illustration of the main effector mechanisms by which altered sensory neurone responsiveness is achieved.

stimulus, for a matter of minutes. However, in the presence of ongoing tissue injury or inflammation, sensitisation may also be prolonged. The sensitising effects of NGF on heat responsiveness of sensory neurones has been particularly well studied. On isolated DRG cells in culture and on sensory neurone terminals studied using a skin-nerve preparation, NGF acutely sensitises many nociceptive neurones, ${ }^{20}$ although the mechanism of sensitisation has variously been ascribed to PKA, PKC, phosphatidylinositol-4,5-biphosphate, and ERK dependent mechanisms. Small diameter sensory neurones chronically exposed to elevated NGF levels (in a NGF over expressing mouse) showed marked heat sensitisation. $^{21}$ While the exact mechanism of sensitisation is not known in this latter case, the data none the less demonstrate that persistent peripheral sensitisation is possible.

\section{ALTERED GENE EXPRESSION IN NOCICEPTORS}

A second form of sensory neurone plasticity involves regulation of gene expression in those neurones. There is now a very large body of experimental data suggesting that such regulation readily occurs as a consequence of tissue injury, most notably persistent injuries associated with peripheral tissue inflammation. The plasticity of gene expression affects many aspects of sensory neurone function, including: genes coding for neurotransmitters released with activity from the central terminals of nociceptors; genes coding for receptors which are transported to both the peripheral and central terminals of sensory neurones; and genes coding for ion channels expressed throughout the neurone and potentially affecting its sensitivity. Genes regulating structural proteins in nociceptors are also affected and this may affect some anatomical features of these neurones.

There are several potentially important signals for this plasticity of gene expression. The most important (and certainly the best studied) is NGF. This molecule is upregulated in many experimental models of inflammation (including those induced by carrageenan and Freund's adjuvant) and in some clinical inflammatory disorders. ${ }^{22-28}$ NGF is known to be internalised following its binding to trkA. In addition to its peripherally sensitising effects discussed above, it is known to be transported retrogradely from peripheral terminals to cell bodies. Evidence from several sources suggests that NGF itself cannot initiate signalling in the cell soma, but that the NGF/trkA complex maintains autophosphorylation and activates transcription factors such as cyclic AMP response element binding protein and Oct-2 (a member of the POU family of transcription factors) that control gene expression. ${ }^{29}{ }^{30}$ The importance of NGF is supported firstly, by its ability (when administered exogenously) to induce changes in gene expression and secondly, from the many studies which have shown that nociceptor plasticity to inflammation is greatly reduced with strategies that block NGF actions. ${ }^{31}$ While the data for NGF are particularly extensive, it is also clear that other neurotrophic factors such as glial cell line derived neurotrophic factor can regulate gene expression in some primary sensory neurones. ${ }^{32}$

\section{CONCLUSIONS}

In summary, there are many ways in which the sensitivity of visceral sensory neurones might be modulated. Some of these are rapid and are triggered by many of the stimuli that normally impinge on the sensory neurones. Other forms of modulation have a slower onset and are more persistent. These frequently involve altered gene expression in the sensory neurones, triggered by altered availability of neurotrophic factors. Altered sensory neurone responsiveness may contribute to pathophysiological states such as irritable bowel syndrome, and the mechanisms leading to sensory neurone sensitisation offer novel targets for the treatment of such disorders.

\section{REFERENCES}

1 England S, Bevan S, Docherty RJ. PGE2 modulates the tetrodotoxin-resistant sodium current in neonatal rat dorsal root ganglion neurons via the cyclic AMP-protein kinase A cascade. J Physiol 1996;495(Pt 2):429-40.

2 Tominaga M, Wada M, Masu M. Potentiation of capsaicin receptor activity by metabotropic ATP receptors as a possible mechanism for ATP-evoked pain and hyperalgesia. Proc Natl Acad Sci U S A 2001;98:6951-6.

3 Cesare P, McNaughton P. A novel heat-activated current in nociceptive neurons and its sensitization by bradykinin. Proc Natl Acad Sci U S A 1996:93:15435-9.

4 Oh SB, Tran PB, Gillard SE, et al. Chemokines and glycoprotein 120 produce pain hypersensitivity by directly exciting primary nociceptive neurons. J Neurosci $2001 ; 21: 5027-35$.

5 Akopian A, Okuse K, Wood JN. Sensory neuron-specific ion channels and receptors. In: Wood J, ed. Molecular basis of pain induction. New York: John Wiley and Sons Ltd, 1999:84-101.

6 Hamilton SG, McMahon SB. ATP as a peripheral mediator of pain. J Auton Nerv Syst 2000;81:187-94.

7 Shu X, Mendell LM. Acute sensitization by NGF of the response of smalldiameter sensory neurons to capsaicin. J Neurophysiol 2001;86:2931-8. 
8 Chuang $\mathrm{HH}$, Prescott ED, Kong $\mathrm{H}$, et al. Bradykinin and nerve growth factor release the capsaicin receptor from Ptdlns $(4,5)$ P2-mediated inhibition. Nature 2001;411:957-62.

9 Khasar SG, McCarter G, Levine JD. Epinephrine produces a beta-adrenergic receptor-mediated mechanical hyperalgesia and in vitro sensitisation of rat nociceptors. J Neurophyiol 1999;81:1 104-12.

10 Aley KO, Levine JD. Role of protein kinase A in the maintenance of inflammatory pain. J Neurosci 1999;19:2181-6.

11 Cesare P, Dekker LV, Sardini A, et al. Specific involvement of PKC-epsilon in sensitization of the neuronal response to painful heat. Neuron 1999;23:617-24.

12 Aley KO, Martin A, McMahon T, et al. Nociceptor sensitisation by extracellular signal-regulated kinases. J Neurosci 2001;21:6933-9.

13 Dai Y, Iwata K, Fukuoka T, et al. Phosphorylation of extracellular signalregulated kinase in primary afferent neurons by noxious stimuli and its involvement in peripheral sensitisation. J Neurosci 2002;22:7737-45.

14 Gold MS, Reichling DB, Shuster MJ, et al. Hyperalgesic agents increase a tetrodotoxin-resistant $\mathrm{Na}^{+}$current in nociceptors. Proc Natl Acad Sci U S A 1996:93:1108-12.

15 England S. Molecular basis of peripheral hyperalgesia. In: Wood J, ed. Molecular basis of pain induction. New York: John Wiley and Sons Ltd, 1999:213-27.

16 Vellani V, Mapplebeck S, Moriondo A, et al. Protein kinase C activation potentiates gating of the vanilloid receptor VR1 by capsaicin, protons, heat and anandamide. J Physiol 2001;534:813-25.

17 Chen C, Bobbin RP. P2X receptors in cochlear Deiters' cells. Br J Pharmacol 1998; 124:337-44

18 Liang YF, Haake B, Reeh PW. Sustained sensitization and recruitment of rat cutaneous nociceptors by bradykinin and a novel theory of its excitatory action. J Physiol 2001;532(Pt 1):229-39.

19 Dmitrieva N, McMahon SB. Sensitisation of visceral afferents by nerve growth factor in the adult rat. Pain 1996;66:87-97.

20 Shu XQ, Mendell LM. Neurotrophins and hyperalgesia. Proc Natl Acad Sci U S A 1999;96:7693-6.
21 Stucky $\mathrm{CL}$, Koltzenburg $M$, Schneider $M$, et al. Overexpression of nerve growth factor in skin selectively affects the survival and functional properties of nociceptors. J Neurosci 1999; 19:8509-16.

22 Aloe L, Tuveri MA, Levi-Montalcini R. Studies on carrageenan-induced arthritis in adult rats: presence of nerve growth factor and role of sympathetic innervation. Rheumatol Int 1992;12:213-16.

23 Donnerer J, Schuligoi R, Stein C. Increased content and transport of substance $\mathrm{P}$ and calcitonin gene-related peptide in sensory nerves innervating inflamed tissue: evidence for a regulatory function of nerve growth factor in vivo. Neuroscience 1992;49:693-8

24 Woolf CJ, Safieh-Garabedian B, Ma QP, et al. Nerve growth factor contributes to the generation of inflammatory sensory hypersensitivity. Neuroscience 1994;62:327-31.

25 Safieh-Garabedian B, Poole S, Allchorne A, et al. Contribution of interleukin1 beta to the inflammation-induced increase in nerve growth factor levels and inflammatory hyperalgesia. Br J Pharmacol 1995;115:1265-75.

26 Lowe EM, Anand P, Terenghi G, et al. Increased nerve growth factor levels in the urinary bladder of women with idiopathic sensory urgency and interstitial cystitis. Br J Urol 1997;79:572-7.

27 Weskamp G, Otten U. An enzyme-linked immunoassay for nerve growth factor (NGF): a tool for studying regulatory mechanisms involved in NGF production in brain and in peripheral tissues. J Neurochem 1987;48:1779-86.

28 Oddiah D, Anand P, McMahon SB, et al. Rapid increase of NGF, BDNF and NT-3 mRNAs in inflamed bladder. Neuroreport 1998;9:1455-8.

29 Kendall G, Brarrai A, Ensor E, et al. Nerve growth-factor induces the oct-2 transcription factor in sensory neurons with the kinetics of an immediate-early gene. J Neurosci Res 1995;40:169-76.

30 Poo MM. Neurotrophins as synaptic modulators. Nat Rev Neurosci $2001 ; 2: 24-32$

31 McMahon SB, Bennett DLH. Trophic factors and pain. In: Wall PD, ed. Textbook of pain. London: Churchill Livingstone, 1999:105-28.

32 Ogun-Muyiwa P, Helliwell R, McIntyre P, et al. Glial cell line derived neurotrophic factor (GDNF) regulates VR1 and substance $P$ in cultured sensory neurons. Neuroreport 1999; 10:2107-1 1 